\title{
Emerging empowerment of international students: how international student literature has shifted to include the students' voices
}

\author{
Alexander Gamst Page ${ }^{1} \cdot$ Sobh Chahboun ${ }^{2}$
}

Published online: 8 March 2019

(C) The Author(s) 2019

\begin{abstract}
Social isolation has been a central focus within international student research, especially with regard to international/host national relations. While a worthy area of study, we argue that the sheer volume of such research stems from the fact that universities' recruitment of foreign students is often justified by the claim that a more international campus will engender crosscultural skills. The main argument of this paper is that, from this perspective, the "point" of such sojourns is seen as social, and any lack of interaction becomes problematic. This is an intellectually respectable position, but it is problematic that it has come to dominate the field to such a degree that the students' own experiences and goals are rarely heard. This paper calls for a de-muting of international students in research, so that more research is oriented by their stated priorities. While there has been a shift in this regard around the turn of the millennium, presumptions as to the purpose of educational sojourns remain and continue to colour research.
\end{abstract}

Keywords International students · Internationalisation · Social isolation · Social networks · Student experience $\cdot$ Agency

\section{Introduction}

The increased global mobility of people, objects, concepts and images has made for a gradually diversifying student body. In tandem with this, we see a growing range of academic literature describing international students (see Byram and Dervin 2008:2-3). This has been dominated by areas such as second language acquisition (Freed 1995; Byram and Dervin 1998; Jackson 2008; Nemoto 2011) and acculturation (Kashima and Loh 2006; Li et al. 2016).

Alexander Gamst Page alexander.gamst.page@ntnu.no

1 Department of Teacher Education, Norwegian University of Science and Technology, Trondheim, Norway

2 Queen Maud University College of Early Childhood Education, Trondheim, Norway 
However, a substantial proportion of international student research is devoted to social isolation, particularly the lack of interaction with host national students (Bochner et al. 1977; Ward and Kennedy 1993; Sam 2000; Pritchard and Skinner 2002; Baba and Megumi 2014; Arthur 2017). This paper suggests that an implicit assumption as to the purpose of these sojourns underlies much of this research, skewing the questions upon which they are based. As we shall see, many commentators on international students seem to pre-suppose that the goal of such sojourns is to foster intercultural cooperation (e.g. Fulbright 1976; Laubscher 1994). This assumption seems to have been taken up by a large proportion of the people writing on international students (e.g. Westwood and Barker 1990; Pritchard and Skinner 2002; Campbell 2012; Kimmel and Volet 2012), to the extent that the students' own motivations and aspirations are rarely heard. The result of this is that a large part of the extant international student research centres on the lack of cross-cultural interaction in their sojourns. The purpose is not to impugn the quality of the research, but to suggest that a more nuanced understanding of the assumptions of purpose in research would be useful. Interestingly, with an increased proliferation of more qualitative approaches, some studies have demonstrated the value of such an altered perspective by de-muting the students themselves and allowing their own presentations of their experiences to set the tone. While the deficit model is still a prevalent perspective, these more recent studies represent an encouraging development where the types of perspectives used are becoming more diverse, more complex, and that the viewpoints of the students themselves are being given more emphasis.

\section{The presentation of purpose in educational sojourns}

While we might suppose that there have always been students involved in higher education outside their countries of origin, the study of international students is one that has, until recently, garnered relatively sparse scholarly attention. However, higher education has undergone a rapid internationalisation since the turn of the twenty-first century (Byram and Dervin 2008; Wu et al. 2015), a process where many universities send and receive higher numbers of international students (Brooks and Waters 2011). It is to be expected that as a phenomenon expands and becomes more salient, so does the scientific attention it attracts. With this in mind, it is not surprising that the last 5 years has seen a particular expansion of the field (e.g. Beech 2015; Prazeres 2017; King and Sondhi 2018; Yang 2018). That being said, it is still a relatively peripheral subject, at least within most social scientific disciplines. However, while all migration is reflective of globalisation processes, the very existence of international students as a phenomenon is especially so. The act of studying in one place with a mind to implementing the acquired capital elsewhere indicates a conceptualisation of knowledge that is not embedded in a local context but is applicable for a wider intellectual space. Increased educational mobility may be seen, in Appadurai's terms, as an intensification of transnational flows that have always been present (1996).

\section{Rhetoric surrounding international student programs}

Partly facilitated by these shared frames of reference and criteria for determining the validity of knowledge, internationals have come to constitute a large proportion of the student body in many countries, partly as a result of various strategies of attracting them. Some countries such as the UK and Australia court international students for economic reasons, charging them 
higher fees. For countries such as Germany, France, Sweden and Norway, the wish for a competitive edge in recruiting skilled individuals, as well as the prestige of being seen as internationally attractive, leads them to offer free tuition to applicants from abroad. The cost of such incentives tends to be justified by pointing out the "self-evident" process by which crosscultural contact engenders understanding, cooperation, tolerance, and may even help prevent war (Fulbright 1976; Bochner et al. 1977; Laubscher 1994). Globalisation is quite often namechecked in this kind of rhetoric, where a typical argument is that interaction with people from other societies will prepare the specialists and leaders of tomorrow for this age of increasing globalisation.

The Nordic countries may be mentioned here, as they comprise some of the few providers of free international education and, unlike countries like Germany, typically offer courses in English. The four major universities of Norway all justify the courting of international students partly as a societal mission to foster intercultural understanding, which would "... solve global challenges connected to climate, energy, health, etc. (SIU 2013:16[our translation])". The Swedish Ministry of Education and Research similarly emphasise social values as a rationale for educational internationalisation, stating that "[b]eing exposed to a cultural situation that may be utterly different from that of the country of origin can be enriching and contribute to self-understanding and understanding of others" (SOU 2018:9). Such sentiments may also be found in the larger Anglophone recipients of international students, such as Australia.

[International education] offers opportunities to build enhanced bilateral and multilateral relationships, which increase cultural awareness and social engagement. In addition, diplomacy is advanced through Australian educated alumni who develop lasting connections at personal, organisational and government levels. All of this is fostering better relationships with our regional neighbours and the rest of the world (Australian Government 2016:7[our italics]).

This rhetoric is echoed within scientific literature (e.g. Altbach 1991; Deardorff 2006; Parsons 2010; Gareis and Jalayer 2018). Here too, it seems to be viewed as self-evident, as it is very often stated matter-of-factly in the opening sections of articles and books dealing with international students. Phrases such as "[t]hey (...) increase our awareness and appreciation for other countries and cultures (Lee and Rice 2007:391)", and "Robust international student presence on campuses has the potential for the internationalization of the curriculum, the development of networks for future recruitment and international relations, as well as the establishment of global economic and diplomatic relationships (Urban and Palmer 2014:3056)" are typical, often appearing in the introductory paragraph. What is notable about such claims is that they are often presented without justification or argument. They are merely presented as unsupported truism. In some cases, we find similar statements accompanied by a citation (e.g. Sam 2000; Kimmel and Volet 2012; Volet and Ang 2012). However, following these citations seem always to ultimately lead to a source of the first kind, i.e. one where it seems taken for granted.

An example of this is Wei et al. (2007):385), who claim that international students play a major role in facilitating cross-national collaboration, citing Heppner (2006) as their source. However, this source does not offer any evidence in this regard. Heppner merely states that the rate of international studies is rising and expresses a hope that this will lead to increased internationalisation. Jindal-Snape and Rientes (2016):1) make a similar claim, citing no fewer than five sources, which are Zhou et al. (2008); Peacock and Harrison (2009); Zhou et al. 
(2010); Burdett and Crossman (2012); and Rientes and Nolan (2014). Here too, following these citations does not lead to any verification, but to unsupported assertions.

Another example of this is Volet and Ang (2012). While writing critically on the way in which internationalisation has been handled, they too assert that it is in itself a major goal of international educational sojourns (2012:21). This is backed up with a quote from Knight and de Wit, who claim that the purpose of international educational sojourns is "to understand, appreciate and articulate the reality of interdependence among nations (environmental, economic, cultural and social) and therefore prepare [those involved] to function in an international and inter-cultural context (Knight and de Wit 1995:13)". While Knight and de Wit go into detail on the various political, economic and cultural rationales which are used to support internationalisation, their paper is a review on the discourses and does not actually present the evidentiary bases for said discourse. Frequently, they do not even provide sources, instead referring to "many studies", which go unnamed.

In other articles, the issue is more subtle. Kimmel and Volet (2012) claim several aims for the internationalisation of higher education, among them learning equality. On this point, they cite De Vita (2000), but the phrasing here can give a slight misrepresentation of De Vita's argument. He follows a multicultural business management classroom and does indeed note that classroom participation is beneficial for the formation of cross-cultural communicative skills. However, he does not claim that this is the aim of international educational sojourns in general.

It should be noted here that we are not arguing that any of these studies are poor works of scholarship, because they are not. Among other things, they provide valuable insights into the experiences of international students, their reluctance to form cross-cultural ties and the psychological impact of this. There is much evidence that international students are socially isolated (Bochner et al. 1977; Sam 2000; Glass and Westmont 2014; Shadowen et al. 2019) and that increased contact with host nationals would increase their networks, and be psychologically beneficial (Kashima and Loh 2006; Yang et al. 2006; Sakurai et al. 2010; Hendrickson et al. 2011; Wu et al. 2015). Neither are we suggesting that internationalisation is a negative, but rather pointing out the similarity in rhetoric between policy makers and researchers, which may indicate that a relatively baseless assumption of purpose has come to influence the direction which research has taken. The value of these studies is in understanding the role of social connections, which they do admirably. The flaw is in assuming that the social connections valued by policy makers must also be the goal of the sojourning students themselves, an assumption that quickly vanishes when the students themselves are given a voice.

\section{The role of methodology}

In short, it seems as though what we are seeing is a conflation of the stated goals of policy makers with those of the university authorities and the students themselves. Such assumptions demonstrate how central the narrative of internationalisation has become in the field of international students, which in turn explains the focus on their social interactions, especially with host nationals. Fostering this cultural shift within the educational institutions is presented as the sole purpose of such sojourns. Therefore, the role of these students is as repositories of exoticism or otherness, so that the host national students can become internationalised through interacting with them. Within this perspective, it becomes problematic that most international students have very limited interactions with host nationals, which is presented as a failing or a deficit. This leads to them being portrayed as passive agents, reactors to external structural 
factors. This may have a number of explanations, but we suggest it is partly due to the dominant methodology, as this goes a long way towards illustrating the intention of the study.

According to Montgomery (2010:19), studies into international students before the 2000s were characterised by large-scale quantitative surveys, typified by that of psychologists Bochner et al. (1977). While psychology as a discipline encompasses individual motivations, in this case, they sought to locate predictors of macroscopic patterns of behaviour. Another of the studies Montgomery (2010) presents as representative is that of Merrick (2004). This was commissioned by the UK Council on International Education (UKCOSA) and as such looks for statistical data usable at a policy-level. It is in the nature of such studies that the framework is laid before seriously engaging with the participants. What information the study is seeking, and what questions are valid have already been decided, and thus also the ways in which the voices of the participants may be expressed. In general, we see a shift some time in the early 2000s towards more qualitative methods, such as in-depth interviews and ethnography, which increasingly focus on the experiences of the students themselves (Montgomery 2010). As these emic perspectives of the students themselves come into focus, so too does their agency (see Montgomery and McDowell 2009; Bennett et al. 2013; Jones 2013; Prazeres 2017). This is natural enough, as a shift from large-scale quantitative studies to more qualitative perspectives simultaneously tightens the focus from the level of structure to that of the individual. With regard to de-muting the participants themselves, anthropological studies seem to have progressed further, both because of their use of ethnography, and their focus on the social realities created by the participants themselves (Fong 2011; Yang 2018; Page 2019).

\section{The deficit model}

As has been stated, there are several research foci concerning international students, but among the most prominent are social connections, and it is especially common to see studies concerning the lack of interaction with host nationals. At most universities where such research has been conducted, international students tend not to interact closely with members of the host community, far less to establish lasting friendships with them. A central and frequently cited study in this model is that of Bochner et al. (1977), where the authors note that, for companionship and friendship, international students greatly favour their co-national peers. This preference, and the resulting lack of contact with host nationals, has been reaffirmed by many (Ward and Kennedy 1993; Sam 2000; Pritchard and Skinner 2002; Montgomery 2010; Wu et al. 2015; Yu and Moskal 2018). Most commonly, international students will establish networks of co-nationals wherever possible and otherwise seem to favour international students from other countries rather than host nationals. One of the few studies which contest this is that of Hendrickson et al. (2011), although by their own admission their findings may be due to an unrepresentative sample. Another study questioning this is that of Montgomery and McDowell (2009:456-7), although their sample is made up of students late in their sojourns, and social isolation tends to be more salient in the early stages. What is noteworthy about many of these studies is the way in which they frame the international student experience in terms of a predetermined set of expectations, and subsequently frame their sojourns as failing to live up to these expectations, a trend which here will be referred to as the deficit model. It should be clear, though, that this model does not mean only focusing on the lack of crosscultural communication, but assuming that this is a failure of the sojourn without considering whether such contact was the goal of the students themselves. 
This perspective never went away, and a focus on the lack of social engagement still dominates the field (Kashima and Loh 2006; Sakurai et al. 2010; Bennett et al. 2013; Wu et al. 2015; Gareis and Jalayer 2018). However, research has become more nuanced, including a broader range of perspectives. For instance, some studies question the overall assertion that conational groupings are a negative phenomenon. We also see some examples of the students themselves reacting to their isolation and some studies of the circumstances in which crosscultural relations are formed. Through such nuancing, we see that the students themselves are imbued with greater agency, a louder voice, and that their own perspectives are given a more central place as a result.

One reason why isolation from the host national community may be less of an issue than some suppose is that international students tend to be sojourners rather than migrants. That is to say that their residence in the host country is typically temporary (King et al. 2010), where many intend to return ( $\mathrm{Lu}$ et al. 2009) or to utilise their educational sojourns as a spring-board for further migrations (Wu and Wilkes 2017). Rather than permanent residency in the receiving country, they are more likely to be seeking social capital translatable to improved employability (Robertson et al. 2018) or less tangible commodities, which shall be discussed later. This may mean that the effort required to form cross-cultural bonds may be seen as less worth the effort than would be the case for migrants intending to stay long-term (Page 2016).

The increased focus on student perspectives may be seen in terms of the underlying assumptions made. As we have seen, statements such as "we are losing sight of the core rationale for internationalization: the promotion of international good will (Gareis and Jalayer 2018:83)" are common, and we would argue they go beyond introductory preamble but comprise an assumption that influences the course of the study. Sherry et al. (2010), for instance, investigate the experiences of international students at the University of Toledo in order to investigate how their situations may be improved with social isolation being one of the areas under investigation. While it is not stated explicitly in the research questions, the introduction of the topic seems to take as its supposition that what must be investigated is what hinders the establishment of bonds rather than how they are promoted. A clearer example of this is found in the work of Volet and Ang (2012) who explored cross-cultural ties in an Australian university. They too asked what was hindering such ties, suggesting that it may be the prejudicial assumptions that international and host national students make about each other. However, they noted that even when these prejudices were dispelled, the students remained unlikely to form cross-cultural connections. From this we see a trend where an assumption as to the desirability of social connections leads to a research question asking in what way they are hindered. Of course, this question is entirely logical considering the base assumption. If the goal is to form social bonds and this does not happen, logically, the formation of bonds is somehow impeded. However, if this base assumption is to be problematized, then the question becomes less valid.

\section{Isolation detrimental?}

First, while it seems fairly conclusive that international students experience social isolation in the early parts of their sojourns, and that this is psychologically detrimental, this factor may be given an undue amount of scholarly attention, due as we have argued to the tacit conflation of the sojourns' goals. In fact, when international students themselves are asked, many present academic achievement as most important to them (Montgomery and McDowell 2009). Others emphasise future earning potential or competitiveness (Fong 2011), or that foreign universities 
may have greater expertise in the students' chosen field (Page 2016, 2019). In all these regards, if such considerations are seen as the main goal of the sojourn, social connections to the host nationals become less important and may even be seen as counterproductive. Montgomery and McDowell (2009) describe the academically focused community of practice that international students establish and compare it to the more casual networks of home students. From this, they question the assumption that the internationals are missing out by not interacting more closely with home students. In fact, they suggest that closer interaction would be detrimental to the community of practice that the international students have established.

Returning to the study of Volet and Ang (2012), the primary prejudice held by the internationals of the Australian students were that they were lazy and that partnering up with them would therefore harm the internationals' academic work. This suggests that, for these students, academic achievement was more important than attaining belonging in their host society. The temporary nature of the psychological pressures experienced may in itself be taken as evidence that connections with host nationals are rarely emphasised. The pressures experienced are usually stronger in the early stages of educational sojourns (Sawir et al. 2008; Campbell 2012; Forbush and Foucault-Welles 2016) and may therefore be absent in a study focusing on the later stages of students' sojourns (e.g. Montgomery and McDowell 2009). The depression-like symptoms many international students experience (Shadowen et al. 2019) seem to dissipate as they establish social networks, the national character of which having a value in itself. In countries that differ substantially from the sending society, the formation of a co-national group might lessen culture shock by allowing international students to interact in a way with which the students are more culturally familiar (Page 2019).

\section{Imagining a global space}

Another recurrent motivation for international student sojourns that more open-ended qualitative studies have revealed is an attempt to reconfigure subjectivity with regard to a concept of global space (Waters 2007; Montgomery 2010; Fong 2011; Jones 2013). These perspectives emphasise the symbolic value with which the international students themselves imbue their sojourns, and subsequently how these sojourns may serve as vehicles for translating the self into a global actor, or to put it another way, as disembedded citizens of an imagined global space. Such perspectives have overtones of identity work and follow the principle that projects of reshaping or redefining one's subjectivity may take many forms, among them education (Mishler 1978) and migration (Dolby and Rizvi 2008; Berg 2011). This is a mode of inquiry which has arisen out of such lenses as transnationalism and globalisation and is one of the youngest perspectives on international students, possibly because the intense internationalisation of higher education is such a recent phenomenon (see Brooks and Waters 2011). It might also be due to the comparative youth of the perspectives of transnationalism and globalisation themselves. The form of globalisation most compatible with this identity work is possibly that of Appadurai (1996), in that the global flow of imaginaries plays a key role in the establishment of the global space and the desire to partake in it. Several researchers (Montgomery 2010; Fong 2011; Jones 2013) suggest that the students imagine a global, cosmopolitan space capable of being appropriated through the attainment of internationally valid knowledge. This is facilitated by the knowledge being acquired abroad, especially in developed countries associated with modernity and globalised cosmopolitanism. Many hope that academic degrees and cross-cultural competence will act as a passport for 
achieving membership into this imagined space (Montgomery 2010), in order to allow symbolic membership into the developed world (Fong 2011).

\section{Creating an elite habitus}

Waters (2007) investigates the creation of what is termed the transnational capitalist class (TNCC). This is a term derived from Marxist theory, denoting a kind of global elite, usually big capitalists, politicians, alpha-consumers and the like (Sklair 2001). According to Waters, there have been a number of studies describing the TNCC (Beaverstock 1996; Findlay et al. 1996; Sklair 2001; Coe et al. 2003), but hers is one of the few dealing with how people first enter this elite class. Drawing on Bourdieu (1977), Waters suggest that the TNCC's shared experience of education, and the acquisition of education practices, creates a common culture which forms the basis of a group identity. She argues that these elite educational institutions, through a spatial and social segregation of students, espouse a particular habitus. As educated corporate, political or consumer elites, this class has a global, outward oriented identity rather than a local or inward oriented one (Waters 2007:479). While this is a more exclusive group than most international students, it nevertheless represents an attempt to see the international student experience on their terms, rather than by standards externally defined. Here also the importance of cross-cultural and cosmopolitan competence is emphasised, as academic credentials are only part of what is needed for the successful advancement to the TNCC. These schools prepare their students for global mobility by providing cultural education, but at the same time, these students mostly socialised with co-nationals to the extent that one interviewee claimed to rarely speak English, even in Canada. Despite the global aspirations of these students, they seem to form cliques of co-nationals similar to those described by earlier studies.

\section{Symbolic membership in the developed world}

Fong's study (Fong 2011) is by far the most extensive of those presented here and possibly one of the larger studies of international students overall. She uses a longitudinal design, interviewing hundreds of youth over a course of many years. Her focus was initially on students within China, but it evolved to encompass their sojourns in other countries. For many, study abroad became a back-up solution to compensate for not making it into the most prestigious universities at home, as the competition within higher education in China is very stiff. The same tendency is seen in other senders of students besides mainland China, such as India (Jones 2013), Hong-Kong (Waters 2007) and Korea (Waters 2008). Symbolic membership does not necessitate that the student must permanently settle abroad after graduation. In fact, many intend to return to China with the hope that with a western degree will give them an edge on the job market. Symbolic membership in the developed world means a certain set of knowledges and skills, as well as globally recognised qualifications. Ideally, this should allow those in possession of this capital to return to China safe in the knowledge that they may leave again should they so decide. Fong uses Sen's (1999) definition of development, which mainly consists of the freedom on the part of the individual to choose one's own life-course. Fong also devotes some space to describing the lives of the Chinese students abroad, which are difficult and rootless and are described as floating lives. On the whole, she presents a somewhat pessimistic image of these sojourns, as many invest a great deal of time and capital into an education that ultimately does not give them the competitive edge for which they were hoping. In fact, recent research casts much doubt as to the true value of higher education for social 
mobility (Hoskins and Barker 2014). This is a somewhat grim contrast to the Waters' students, who are almost guaranteed to succeed due to the great amount of capital investments made by their families. It is remarkable, however, how much faith these students have that going abroad will improve their lives, and also how driven they are by imagination, both of what the developed world is, and how they can partake in it. While pessimistic, the analysis is driven by the experiences of the students themselves.

\section{Cliques and cosmopolitan identity creation}

The tendency to form cliques is strong for international students, despite the awareness that forming such co-national groupings may be detrimental to one's acquisition of cross-cultural competence and subsequently the attainment of global identity (Rizvi 2005; Papastephanou 2013). This dilemma is captured by the work of Jones (2013). She describes how Tamil students utilise their sojourns in the UK as a way of attaining a cosmopolitan experience, as well as increasing their attractiveness on the Indian job market. She distinguishes between those students who tend towards co- or cross-ethnic fellowship. Those who are more interested in building up cross-cultural competence make a greater effort to fraternise with people from other countries, and avoid falling into Tamil cliques. They are very conscious of their own ability to attain cross-cultural competence and the detrimental effect parochialism would have on this, a sentiment that Jones (2013:424) notes is close to the official position of the universities themselves. The role of international/host national relations in the attainment of a cosmopolitan identity is further complicated by the othering effect of having identity labels placed upon one by the host national society. Among Chinese international students in Germany, this led to an internal differentiation where the participants communicated their cosmopolitan identities by defining themselves as different from uneducated migrants (Bilecen 2013).

Such accounts of cliques and social isolation may bear a resemblance to the deficit model, but by focusing on those who defy the norm, we gain a greater understanding of the mechanisms at work. We understand that there is no automacy in their social isolation, but that it might rather be a matter of maximising behaviour, where students with different priorities focus their energies in different areas. We see here a more nuanced account of how cross-cultural interaction might work towards the students' own expressed goals, as well as a more well-defined reason why they would want to make the investment of time and energy to establishing more hard-won social relationships. Jones describes these goals as stemming from imaginaries akin to those described by Appadurai (1996). She emphasises the influence that images have on her informants, for instance seeing pictures in glossy magazine of well-dressed urbanites. The ubiquity of images such as this play a great role in the formation of cognitive models to which the students aspire.

\section{Conclusion}

These criticisms share a number of similarities, but the most interesting for this study is that they undermine the a priori assumption that the primary goal of educational institutions and the students themselves are one and the same. Doubtless, this comes from a place of good intentions. The appealing thing about defining such issues as clear, uncontroversial problems is that this allows for the construction of solutions. It is this attempt to improve people's lives 
that seem to underlie a great deal of the research rather than an attempt to disenfranchise them. However, when one assumes someone's needs without letting them speak for themselves, this will often be the result. We see from other research where students' voices are foregrounded, in which their own experiences are more complex. International students come for a number of reasons (see Beech 2015), and while learning about the host culture and making friends may be among them, they are not the only ones. Throughout the more recent studies, the voices of the international students themselves have been heard, and from this, the deficit model is problematized. Once we realise that the students themselves may have different goals than those of the educational institutions, then their lack of integration with the host nationals ceases to be seen as a failure state. The theme of social isolation is still very much present in international student literature, although it tends no longer to be centre stage and no longer the focus of the literature in and of itself. Rather, it is part of the landscape within which scientific descriptions take place. Rather than simply focusing on the limitations of their situations, an increasing body of research shows how they react to these limitations and attempt to overcome them.

The texts presented here illustrate shifting trends in the way international students are presented and who is speaking for them. Possibly, this shift is a result of the blurring of academic boundaries where a wider range of perspectives are accruing in each discipline. By this token, what is here, described as an empowerment of the subjects of research, might rather be an effect of seeing these subjects from numerous perspectives and thus seeing them as more complete human beings. Be that as it may for now, the argument here has been on two main dimensions of empowerment. Firstly, the students are portrayed increasingly as interactors with a certain amount of agency rather than passive reactors. Secondly, they are increasingly called on to speak for themselves.

In the research following what is here described as the deficit model, the norm was that students were portrayed as passive reactants and ones that had failed to live up to some predetermined requirement at that. This requirement was not set by the students themselves, but was a result of what others, maybe policy makers or university authorities, took to be the purpose of higher educational sojourns. As we have seen, this purpose revolved around the interaction between the international and the host national students, and from this, it is natural that the relative scarcity of these interactions were seen as a failure of the sojourns themselves. However, by demuting the students, it became clear that they may travel for a wide range of reasons, often revolving around improving their lives materially through academic accomplishment and increased earning power or through the self realisation of attaining a global identity.

Another way of framing the difference between the general trend in research and these selected studies is that the former focus on student obligation to society and the latter on student desires. We suggest that studies in this most recent vein are among the most exciting and promising within the field of international student migration. The focus on the students' desires and concepts makes for an actor-driven perspective that allows for agency and illustrates the complex interplay of factors that inform the migrant experience. These studies we have dealt with in this section have also largely avoided the pitfall of seeing the students as fully empowered, allowing for an interplay of agency within a system over which they have little direct control. In taking desire as a concept, these studies also avoid the pitfalls which have been common to migration studies of reducing movements to an economic maximising behaviour (e.g. Ravenstein 1895; Lee 1966; Borjas 1989). The concept of desire allows researchers to combine economic, social and cultural factors and take into account both the 
information and misinformation of the students themselves. It also has much in common with social constructivist perspectives in that these desires are created in interplay between the individuals and the society in which they find themselves and from the local appropriation of globally flowing imaginaries.

\section{Suggestions for future research}

As is generally the case, but which often seems overlooked in most research fields having to do with migration and mobility, the investigation of international students is complex, and there are a multitude of "realities" that may be grasped. We can view such topics on a systemic level, a global level, a community level, etc. We would hazard the opinion that this only makes such fields more exciting, but also places a great demand on the researchers. It mandates an openness to other perspectives and other guiding philosophies. The short-term and long-term effects may be different, and global trends might not mean much to the single individual. Because of this, it is important that a multiplicity of research designs be used so that the larger picture is revealed. In this regard, international student research has been somewhat parochial for a long time. A very narrow type of questions seems to have been granted legitimacy, which was also the case for the perspectives used. Based on this, we would suggest that the broad sweep of studies on international students would be improved by de-muting the subjects of the research themselves. There is some indication that this may be happening, which is a view taken, not from any individual study, but from a broader overview of research trends. Indeed, we are not the first to call for a greater focus on the students themselves in research (e.g. Baláž and Williams 2004; Kim 2015).

What we observe seems to be a sharpening of focus from a systemic level to an individual, and as such, it is natural that we see more studies focusing on individual agency. However, while we welcome this development, we must be wary of our own tendency for overcompensation. While a shift towards a less passive view of the students is largely positive, there is a danger that the pendulum swing of academic focus may carry our perspective too far over to the other side. To the extent that this shift points to studies investigating students based on pretheoretical understandings about agency, this may be counter-productive, as it cannot be denied that international students, like all migrants, are susceptible to laws, policies, regulations, as well as cultural and societal idiosyncrasies of both sending and receiving societies. Similar to the synthesis we see in the structure vs. agency debate, what is needed is research that merges these perspectives of students disempowered by the social and administrative systems wherein they find themselves, and the perspectives of empowered agency, accounting both for their freedom and constraint.

Open Access This article is distributed under the terms of the Creative Commons Attribution 4.0 International License (http://creativecommons.org/licenses/by/4.0/), which permits unrestricted use, distribution, and reproduction in any medium, provided you give appropriate credit to the original author(s) and the source, provide a link to the Creative Commons license, and indicate if changes were made.

Publisher's note Springer Nature remains neutral with regard to jurisdictional claims in published maps and institutional affiliations. 


\section{References}

Altbach, P. G. (1991). Impact and adjustment: foreign students in comparative perspective. Higher Education, 21(3), 305-323.

Appadurai, A. (1996). Modernity at large. Minneapolis, MA: University of Minnesota Press.

Arthur, N. (2017). Supporting international students through strengthening their social resources. Studies in Higher Education, 42(5), 887-894.

Australian Government. 2016. National Strategy for international education. https://nsie.education.gov. au/sites/nsie/files/docs/national_strategy_for_international_education_2025.pdf Accessed 18 February 2019.

Baba, Y., \& Megumi, H. (2014). Home away home: better understanding of the role of social support in predicting cross-cultural adjustment among international students. College Student Journal, 48(1), 1-15.

Baláž, V., \& Williams, A. M. (2004). 'Been there, done that': international student migration and human capital transfers from the UK to Slovakia. Population, Space and Place, 10(3), 217-237.

Beaverstock, J. V. (1996). Migration, knowledge and social interaction: expatriate labour within investment banks. Area, 28(4), 459-470.

Beech, S. E. (2015). International student mobility: the role of social networks. Social and Cultural Geography, 16(3), 332-350.

Bennett, R. J., Volet, S. E., \& Fozdar, F. E. (2013). "I'd say it's kind of unique in a way": the development of an intercultural student relationship. Journal of Studies in International Education, 17(5), 533-553.

Berg, M. L. (2011). Diasporic generations: memory, politics and nation among Cubans in Spain. Oxford: Berghahn Books.

Bilecen, B. (2013). Negotiating differences: cosmopolitan experiences of international doctoral students. Compare: A Journal of Comparative and International Education, 43(5), 667-688.

Bochner, S., McLeod, B., \& Lin, A. (1977). Friendship models of overseas students: a functional model. International Journal of Psychology, 12(4), 277-294.

Borjas, G. J. (1989). Economic theory and international migration. International Migration Review, 23(3), 457485.

Bourdieu, P. (1977). Outline of a theory of practice. Cambridge: Cambridge University Press.

Brooks, R., \& Waters, J. (2011). Student Mobilities, migration and the Internationalzation of higher education. New York, NY: Palgrave Macmillan.

Burdett, J., \& Crossman, J. (2012). Engaging international students. Quality Assurance in Education, 20(3), 207222.

Byram, M., \& Dervin, F. (1998). Language learning in intercultural perspectives: approaches through Drama and ethnography. Cambridge: Cambridge University Press.

Byram, M., \& Dervin, F. (2008). Introduction. In M. Byram \& F. Dervin (Eds.), Students, staff and academic mobility in higher education. Newcastle: Cambridge Scholars Publishing.

Campbell, N. (2012). Promoting intercultural contact on campus: a project to connect and engage international and host students. Journal of Studies in International Education, 16(3), 205-227.

Coe, N. M., Kelly, P. F., \& Olds, K. (2003). Globalization, transnationalism and the Asia-Pacific. In J. Peck \& H. W.-c. Yeung (Eds.), Remaking the Global Economy: economic-Geographical Perspectives. London: Sage.

De Vita, G. (2000). Inclusive approaches to effective communication and active participation in the multicultural classroom. Active Learning in Higher Education, 1, 168-180.

Deardorff, K. K. (2006). Identification and assessment of intercultural competence as a student outcome of internationalization. Journal of Studies in International Education, 10(3), 241-266.

Dolby, N., \& Rizvi, F. (2008). Introduction. In N. Dolby \& F. Rizvi (Eds.), Youth moves. New York, NY: Routledge.

Findlay, A. M., Li, F. L. N., Jowett, A. J., \& Skeldon, R. (1996). Skilled international migration and the Global City: a study of expatriates in Hong Kong. Transactions of the Institute of British Geographers, 21(1), 4961.

Fong, V. L. (2011). Paradise redefined: transnational Chinese students and the quest for flexible citizenship in the developed world. Stanford, CA: University of Stanford Press.

Forbush, E., \& Foucault-Welles, B. (2016). Social media use and adaptation among Chinese students beginning to study in the United States. International Journal of Intercultural Relations, 50, 1-12.

Freed, B. F. (1995). Second language Acquisition in a Study Abroad Context. Amsterdam: John Benjamins Publishing.

Fulbright, J.W. (1976). The Most Significant and Important Activity I Have Been Priveliged to Engage in during My Years in the Senate. Annals, AAPSS, 424, march 1976.

Gareis, E., \& Jalayer, A. (2018). Contact effects on intercultural friendship between east Asian students and American domestic students. In J. Ma \& M. A. Garcia-Murillo (Eds.), Understanding international students from Asia in American Universities (pp. 83-106). Cham: Springer. 
Glass, C. R., \& Westmont, C. M. (2014). Comparative effects of belongingness on the academic success and cross-cultural interactions of domestic and international students. International Journal of Intercultural Relations, 38, 106-119.

Hendrickson, B., Rosen, D., \& Aune, R. K. (2011). An analysis of friendship networks, social connectedness, homesickness, and satisfaction levels of international students. International Journal of Intercultural Relations, 35(3), 281-295.

Heppner, P. P. (2006). The benefits and challenges of becoming cross-culturally competent councelling psychologists: presidential address. The Councelling Psychologist, 34(1), 147-172.

Hoskins, K., \& Barker, B. (2014). Education and social mobility: dreams of success. London: Institute of Education Press.

Jackson, J. (2008). Language, identity and study abroad: sociocultural perspectives. Berkeley, CA: University of California Press.

Jindal-Snape, D., \& Rientes, B. (2016). Understanding multiple and multi-dimensional transitions of international higher education students. In D. Jindal-Snape \& B. Rienties (Eds.), Multi-dimensional transitions of international students to higher education. New York, NY: Routledge.

Jones, D. (2013). Cosmopolitans and 'cliques': everyday socialisation amongst Tamil students and young professional migrants to the UK. Ethnicities, 13(4), 420-437.

Kashima, E., \& Loh, E. (2006). International students' acculturation: effects of international, conational, and local ties and need for closure. International Journal of Intercultural Relations, 30(4), 471-485.

Kim, S. (2015). The influence of social relationships on international students' intentions to remain abroad: multi-group analysis by marital status. International Journal of Human Resource Management, 26(14), 1848-1864.

Kimmel, K., \& Volet, S. E. (2012). University students' perception of and attitudes towards culturally diverse group work: does context matter? Journal of Studies in International Education, 16(2), 157-181.

King, R., \& Sondhi, G. (2018). International student migration: a comparison of UK and Indian students' motivations for studying abroad. Globalisation, Societies and Education, 16(2), 176-191.

King, R., Findlay, A., \& Ahrens, A. (2010). International student mobility literature review. Stoke Gifford: HEFCE.

Knight, J., \& de Wit, H. (1995). Strategies for internationalisation of higher education: historical and cultural perspectives. In H. de Wit (Ed.), Strategies for the internationalisation of higher education: a comparative study of Australia, Canada, Europe and the United States of America (pp. 5-32). Luna Negra: Amsterdam.

Laubscher, M. R. (1994). Encounters with difference: student perceptions of the role of out-of-class experiences in education abroad. Westport, CT: Greenwood.

Lee, E. S. (1966). A theory of migration. Demography, 3(1), 47-57.

Lee, J., \& Rice, C. (2007). Welcome to America? International student perceptions of discrimination. Higher Education, 53(3), 381-409.

Li, J., Marbley, A. F., Bradley, L. J., \& Lan, W. (2016). Attitudes toward seeking professional counseling services among Chinese international students: acculturation, ethnic identity, and English proficiency. Journal of Multicultural Counseling and Development, 44(1), 65-76.

Lu, Y., Li, Z., \& Schissel, B. (2009). To stay or return: migration intentions of students from People's republic of China in Saskatchewan, Canada. International Migration and Integration, 10, 283-310.

Merrick, B. (2004). Broadening our horizons: international students in UK universities and colleges. London: UKCOSA.

Mishler, M. M. (1978). Education and identity. Oxford Review of Education, 4(2), 197-203.

Montgomery, C. (2010). Understanding the international student experience. Bodmin: Palgrave Macmillan.

Montgomery, C., \& McDowell, L. (2009). Social networks and the international student experience: a community of practice? Journal of Studies in International Education, Social networks and the international student experience: a community of practice, 13(4), 455-466.

Nemoto, H. (2011). The management of intercultural academic communication: student exchanges between Japanese and Australian universities. Newcastle: Cambridge Scholars Publishing.

Page, A. G. (2016). Moorings and Disembeddedness: the search for modern subjectivity and the need for belonging among Chinese international students in Norway. Doctoral Thesis, NTNU.

Page, A. G. (2019). Ethnic enclaves transcending space: Chinese international students' social networks in a European University town. Asian Ethnicity. https://doi.org/10.1080/14631369.2019.1570816.

Papastephanou, M. (2013). Being and becoming cosmopolitan: higher education and the cosmopolitan self. International Journal of Higher Education, 2(2), 184-194.

Parsons, L. R. (2010). The effects of an Internationalized University experience on domestic students in the United States and Australia. Journal of Studies in Internationalized Education, 14(4), 313-334. 
Peacock, N., \& Harrison, N. (2009). "It's so much easier to go with what's easy": "Mindfulness" and the discourse between home and international students in the United Kingdom. Journal of Studies in International Education, 13(4), 487-508.

Prazeres, L. (2017). Challenging the comfort zone: self-discovery. Everyday practices and international student mobility to the global south. Mobilities, 1(6), 908-923.

Pritchard, R. M. O., \& Skinner, B. (2002). Cross-cultural partnerships between home and international students. Journal of Studies in International Education, 6(4), 323-353.

Ravenstein, E. G. (1895). The laws of migration. Journal of the Statistical Society of London, 48(2), 167-235.

Rientes, B., \& Nolan, E. (2014). Understanding friendship and learning networks of international and host students using longitudinal social network analysis. International Journal of Intercultural Relations, 41, $165-180$.

Rizvi, F. (2005). International education and the production of cosmopolitan identities. http://hdl.handle.net/2142 /3516. Accessed 18 Feb 2019.

Robertson, S., Harris, A., \& Baldassar, L. (2018). Mobile transitions: a conceptual framework for researching a generation on the move. Journal of Youth Studies, 21(2), 203-217.

Sakurai, T., McCall-Wolf, F., \& Kashima, E. S. (2010). Building intercultural links: the impact of a multicultural intervention programme on social ties of international students in Australia. International Journal of Intercultural Relations, 34(2), 176-185.

Sam, D. L. (2000). Satisfaction with life among international students: an exploratory study. Social Indicators Research, 53(3), 315-337.

Sawir, E., Marginson, S., Deumert, A., Nyland, C., \& Ramia, G. (2008). Loneliness and international students: an Australian study. Journal of Studies in International Education, 12(2), 148-180.

Sen, A. (1999). Development as Freedom. New York, NY: Random House.

Shadowen, N. L., Williamson, A. A., Guerra, N. G., Ammigan, R., \& Drexler, M. L. (2019). Prevalence and correlates of depressive symptoms among international students: implications for university support offices. Journal of International Students, 9(1), 130-149.

Sherry, M., Thomas, P., \& Hong, C. W. (2010). International students: a vulnerable student population. Higher Education, 60(1), 33-46.

SIU. (2013). Internasjonal profil? Strategier for internasjonalisering ved norske universiteter og høyskoler. DOI: file://home.ansatt.ntnu.no/page/Nedlastinger/SIU-rapport-3-2013-Internasjonal-Profil-Strategier-for-int-vednorske-univ-og-h\%C3\%B8yskoler.pdf Accessed 18 February 2019.

Sklair, L. (2001). The transnational capitalist class. Oxford: Blackwell.

SOU. (2018). Internationalisation of Swedish Higher Education and Research - A Strategic Agenda. Doi: https://www.government.se/48fc30/contentassets/4df6aeabd2bd4f5dbbf69210f786e133 /internationalisationagenda.pdf Accessed 18 February 2019.

Urban, E. L., \& Palmer, L. B. (2014). International students as a resource for internationalization of higher education. Journal of Studies in International Education, 8(4), 305-324.

Volet, S. E., \& Ang, G. (2012). Culturally mixed groups on international campuses; an opportunity for intercultural learning. Higher Education Research and Development, 31(1), 21-37.

Ward, C., \& Kennedy, A. (1993). Where's the "culture" in cross-cultural transition? Comparative studies in sojourner adjustment. Journal of Cross-Cultural Psychology, 24(2), 221-249.

Waters, J. L. (2007). 'Roundabout routes and sanctuary schools': the role of situated educational practices and habitus in the creation of transnational professionals. Global Networks, 7(4), 477-497.

Waters, J. L. (2008). Education, migration and cultural capital in the Chinese Diaspora. Amherst, NY: Cambria Press.

Wei, M., Heppner, P., Mallen, M. J., Ku, T., Liao, K. Y., \& Wu, T. (2007). Acculturative stress, perfectionism, years in the United States, and depression among Chinese international students. Journal of Counseling Psychology, 54(4), 385-394.

Westwood, M., \& Barker, M. (1990). Academic achievement and social adaptation among international students: a comparison groups study of the peer-pairing program. International Journal of Intercultural Relations, 14(2), 251-263.

Wu, C., \& Wilkes, R. (2017). International students' post-graduation migration plans and the search for home. Geoforum, 80, 123-132.

Wu, H., Garza, E., \& Guzman, N. (2015). International students' challenges and adjustment to college. Education Research International. https://doi.org/10.1155/2015/202753.

Yang, P. (2018). Compromise and complicity in international student mobility: the ethnographic case of Indian medical students at a Chinese university. Discourse: Studies in the Cultural Politics of Education, 39(5), 694-708. 
Yang, R. P., Noels, K. A., \& Samure, K. D. (2006). Multiple routes to cross-cultural adaption for international students: mapping the paths between self-construals, English language confidence and adjustment. International Journal of Intercultural Relations, 30(4), 487-506.

Yu, Y., \& Moskal, M. (2018). Missing intercultural engagements in the university experiences of Chinese international students in the UK. Compare: A Journal of Comparative and International Education. https://doi.org/10.1080/03057925.2018.1448259.

Zhou, Y., Jindal-Snape, D., Topping, K., \& Todman, J. (2008). Theoretical models of culture shock and adaptation in international students in higher education. Studies in Higher Education, 33(1), 63-75.

Zhou, Y., Jindal-Snape, D., Todman, J., Topping, K., \& Jindal-Snape, D. (2010). Cultural and pedagogical adaptation during transition from Chinese to UK universities. In D. Jindal-Snape (Ed.), Educational transitions: moving stories from around the world (pp. 186-204). London: Routledge. 